\title{
Characterisation of Heat Losses in Zero Emission Buildings (ZEB) in Cold Climate
}

\author{
Johannes Brozovsky*, Niki Gaitani, Arild Gustavsen \\ Department of Architecture and Technology, NTNU, Trondheim, Norway \\ *Corresponding e-mail: johannes.brozovsky@ntnu.no
}

\begin{abstract}
It is well known that urban districts and neighbourhoods can form their own microclimate that can affect the energy balances of buildings significantly. In order to assess the effects of climatic parameters on a building's performance, detailed knowledge about the energy balance of buildings is essential. In this study, the distribution of heat losses in a validated simulation model of a Zero Emission Building (ZEB) was analysed. The model was set to eight different cold climate locations and climate datasets to investigate the influence of wind and the building usage (residential and office building).

The results show that in residential buildings envelope transmission, especially through windows and walls, dominate a typical ZEB's energy losses. In office buildings, ventilation losses gain relevance due to more stringent requirements for ventilation rates. Wind sheltering can lower heat losses by $1.9 \%$ to $8.3 \%$, depending on location and weather data.
\end{abstract}

\section{Introduction}

Climate and the environment where buildings are located determine their thermal behaviour and final energy use. Thus, it affects the selection of materials, technologies, concepts, or techniques in order to guarantee the buildings' energy efficiency. Energy uses that are influenced by climate are primarily space heating and cooling. Space heating is responsible for around $70 \%$ of final energy use (Building Performance Institute Europe, 2011).

It is widely accepted that urban microclimate and in particular the urban heat island (UHI), have a large influence on a building's energy balance (Oke et al., 2017). Mainly, the UHI effect is described as a phenomenon to be mitigated, as it is regarded to obstruct the effectiveness of natural ventilation and to cause outdoor discomfort, higher need for cooling, or even higher mortality rates during summertime (Moonen et al., 2012). But the UHI is not necessarily detrimental but can be favourable especially in cold climate conditions, where heating energy use typically accounts for the largest fraction of a building's energy demand over the year. Warmer night-time and winter temperatures can thus lead to lower heating demands and increased outdoor thermal comfort (Watkins et al., 2007). Most energy efficiency measures, such as the Energy Performance of Buildings Directive in the European Union (EU), focus on the building scale, demanding for example nearly zero energy buildings. The Research Centre on Zero Emission Neighbourhoods in Smart Cities (FME ZEN) however, pursues a different goal. Founded by the Norwegian University of Science and Technology (NTNU) and SINTEF, it aims to reach an overall zero emission balance over a neighbourhood's life cycle (ZEN). Hence, ZENs and ZEBs are of particular importance for reaching the EU's climate goals.

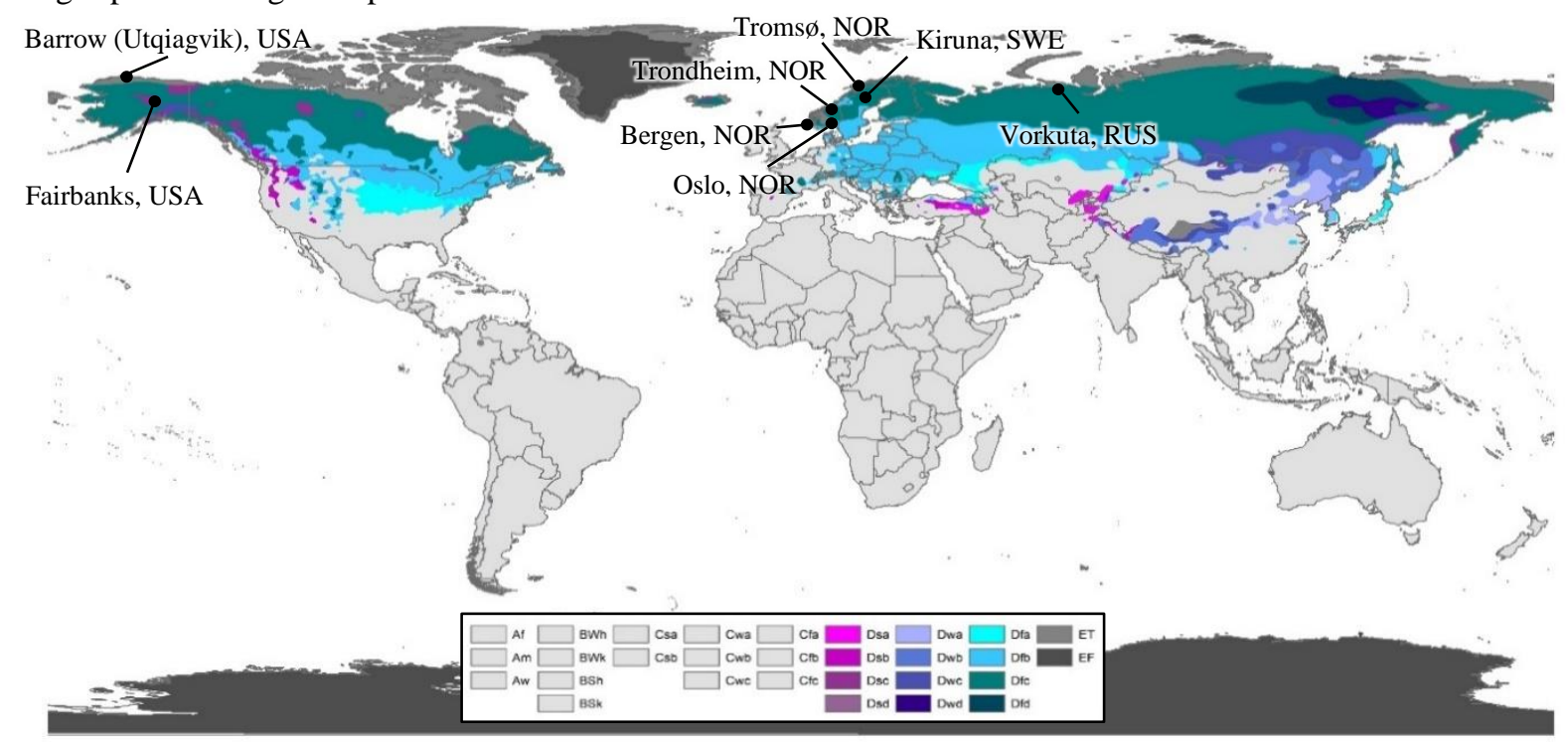

Figure 1: Polar and cold climate regions according to the data from Peel et al. (2007). 
Therefore, characterizing the distribution of heat losses in a ZEB and their dependency on climate data will indicate, which microclimatic parameters are the most critical to address in the ZEN context. It can furthermore help architects and planners in the design of ZEBs with respect to different climate parameters.

Commonly, the heat losses of a building are categorized as follows:

\section{- Building envelope losses}

are defined as the heat flux from inside to outside over the floor, roof, external walls, doors, windows, and thermal bridges. The losses are caused by heat transfer via conduction through the building parts, and convection as well as longwave radiation exchange on their inner and outer surfaces.

- Infiltration losses

are unwanted flows of air through cracks and other passages in the building envelope. They cause additional energy use for heating the incoming outdoor air

\section{- Ventilation losses}

occur when outdoor air is supplied either via natural ventilation or a mechanical ventilation system (MVS) into the building. In order to keep losses as low as possible, often a heat recovery unit (HRU) is used.

\section{ZEB Living Laboratory}

The ZEB Living Living Laboratory (LL) is a $100 \mathrm{~m}^{2}$ detached house test facility on the NTNU campus in Trondheim, Norway (see Figure 2 and Figure 3). As the name implies, zero emission buildings (ZEB) are not targeting energy use as a criterion, at least not primarily, but focus on the reduction of GHG-emissions, which are first and foremost responsible for climate change (Edenhofer, 2014). A ZEB aims to produce enough renewable energy to compensate for the building's greenhouse gas emissions over its life span (Hestnes and Eik-Nes, 2017). This does not only demand the use of renewable energy on site but also promotes energy efficiency measures and the choice of building materials and products according to a life cycle assessment.

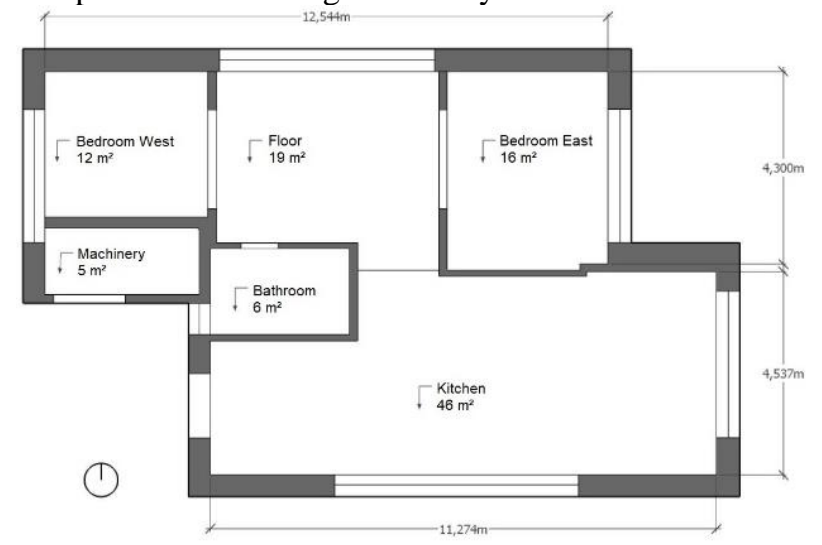

Figure 2: Floor plan of the ZEB Living Laboratory.

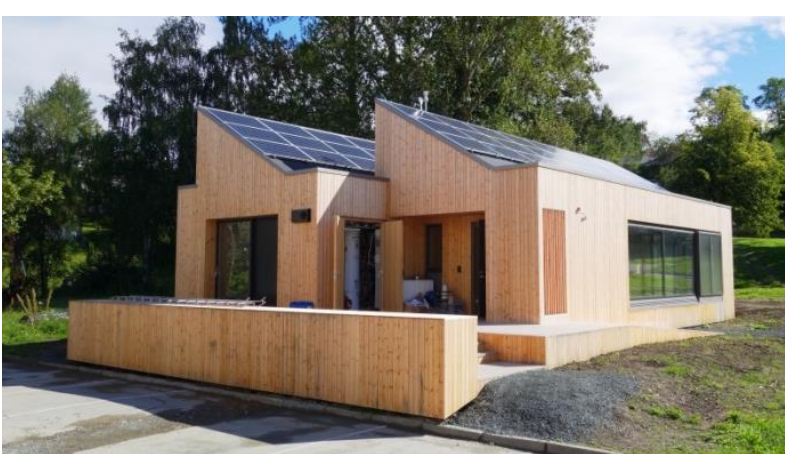

Figure 3: The ZEB LL from outside (photo by Katrine Peck Sze Lim).

The LL was designed to host people for behavioural studies in interaction with zero emission technology. In several experiments, the building has been home for families, couples and single persons of different age and over different periods of time. The building is equipped with a heat pump, several smart home appliances, a PV system on the roof and several sensors to monitor the building's energy consumption and production, and local weather conditions. The building envelope is well insulated and airtight. A double skin window with a ventilated gap is installed on the south façade (Goia et al., 2015). Table 1 shows the building-physical properties of the LL's envelope.

Table 1: Building-physical properties of the ZEB LL.

\begin{tabular}{|c|c|c|}
\hline & Value & Unit \\
\hline Wall U-value & 0.16 & {$\left[\mathrm{~W} /\left(\mathrm{m}^{2} \mathrm{~K}\right)\right]$} \\
Floor U-value & 0.11 & {$\left[\mathrm{~W} /\left(\mathrm{m}^{2} \mathrm{~K}\right)\right]$} \\
Roof U-value & 0.11 & {$\left[\mathrm{~W} /\left(\mathrm{m}^{2} \mathrm{~K}\right)\right]$} \\
Windows (south) U-values & $0.65 / 0.69$ & {$\left[\mathrm{~W} /\left(\mathrm{m}^{2} \mathrm{~K}\right)\right]$} \\
Windows (north) U-values & 0.97 & {$\left[\mathrm{~W} /\left(\mathrm{m}^{2} \mathrm{~K}\right)\right]$} \\
Windows (east/west) U-values & 0.80 & {$\left[\mathrm{~W} /\left(\mathrm{m}^{2} \mathrm{~K}\right)\right]$} \\
g-value & 0.5 & {$[-]$} \\
Infiltration $\mathrm{n}_{50}$ & 0.7 & {$[\mathrm{ACH}]$} \\
Normalized thermal bridge & 0.03 & {$\left[\mathrm{~W} / \mathrm{m}^{2} \mathrm{~K}\right]$} \\
\hline
\end{tabular}

Because in the following simulation results, heating demands will not be looked into, but only the heat balance of gains and losses, a detailed description of internal loads and occupancy is not necessary. To shorten the duration of the simulations, the existing heat pump model with its complex control strategies was replaced by a much faster simulating basic heating system, as this does not affect the distribution of the heat losses.

With regard to the MVS, the operation times and ventilation rates are of particular importance, as those will influence the ventilation losses. As a basis for the model, the Norwegian Standard SN/TS 3031:2016 has been used (see Table 2). The standard is the basis for calculating a building's energy demand in a transient simulation program. On the one hand, by not adjusting the simulation model to the country-specific requirements, the distribution of heat losses is not fully realistic for the locations (except for Norway in this case). On the other hand, by using the same input data for the building, it is possible to highlight the effects of the locations' climatic differences, on which this paper is focusing on. 
Table 2: Ventilation rates and times of operation according to SN/TS 3031:2016.

\begin{tabular}{|l|c|c|}
\hline & Residential & Office* \\
\hline Operation & $\begin{array}{c}\text { Mon-Sun, } \\
0: 00-24: 00\end{array}$ & $\begin{array}{c}\text { Mon-Fri, } \\
7: 00-19: 00\end{array}$ \\
\hline $\begin{array}{l}\text { Ventilation rate } \\
\text { during operation }\end{array}$ & $\begin{array}{c}\text { Bedroom: } 26 \mathrm{~m}^{3} / \mathrm{h} \\
\text { per sleeping place** } \\
\text { Else: } 1.2 \mathrm{~m}^{3} /\left(\mathrm{hm}^{2}\right)\end{array}$ & $7 \mathrm{~m}^{3} /\left(\mathrm{hm}^{2}\right)$ \\
\hline $\begin{array}{l}\text { Ventilation rate } \\
\text { outside operation }\end{array}$ & - & $2 \mathrm{~m}^{3} /\left(\mathrm{hm}^{2}\right)$ \\
\hline $\begin{array}{l}\text { * For the office, a constant air volume (CAV) system was } \\
\text { modelled with a time control } \\
\text { ** Requirement by the Norwegian Building Authority (2017) }\end{array}$ \\
\hline
\end{tabular}

\section{Method}

In this study, the energy losses of a ZEB, located in Trondheim, Norway, are analysed for selected cold climate conditions with the use of building energy performance simulation (BEPS). For that, a simulation model of the investigated building is set to eight different cold climate locations (Oslo, Bergen, Trondheim and Troms $\varnothing$ in Norway, Kiruna in Sweden, Fairbanks and Barrow in Alaska and Vorkuta in Russia; see Figure 1) in the BEPS program IDA Indoor Climate and Energy (IDA ICE) (Bring et al., 1999).

Most commonly, simulation studies use generic building models. In this study, the simulation model of the LL has been mainly developed, updated and calibrated by doctoral and master students at the NTNU in Trondheim in their theses and is used for several research purposes. It is already validated for Trondheim weather conditions. Compared to using an invalidated, generic building model, this study is expected to deliver more reliable results on heat losses in a ZEB. However, using a model outside of its validated domain of application can still induce errors (Sargent, 2013).

The output from IDA ICE v. 4.8 will be used to categorise heat losses, evaluate their magnitudes and dependencies on the locations' climate and to investigate energy balances of building parts. It is furthermore used to investigate the influence of different wind conditions according to ASHRAE wind profiles (American Society of Heating, Refrigerating and Air-Conditioning Engineers, 2009) and wind-induced infiltration according to the AIVC database (Liddament, 1986).

In this study, both heat gains and losses are considered. Particular attention has to be given to the windows as they are able to let solar radiation pass through the building envelope and thus to "generate" energy gains. With the definitions from above, heat losses occur all year round, even in summer, when they may be considered favourable. This can be the case for example during nighttime-ventilation when the cooler outdoor temperatures are used to cool the warmer indoor air to its set point temperature. In the same way, as those losses should not be considered detrimental, not all gains can be considered useful. In summer, when indoor temperatures are generally higher, heat gains from solar irradiation contribute to overheating and are thus classified as detrimental in this specific case. But especially in the transitional seasons, solar gains can reduce a building's heating demand significantly. Therefore, a rule based on the zone's indoor air temperature indicates when heat gains and losses are counted. There are two indoor temperature thresholds from where losses or gains are metered. The threshold temperature for heat losses was determined to be $21.5^{\circ} \mathrm{C}$ and for gains $23.5^{\circ} \mathrm{C}$ (see Figure 4).

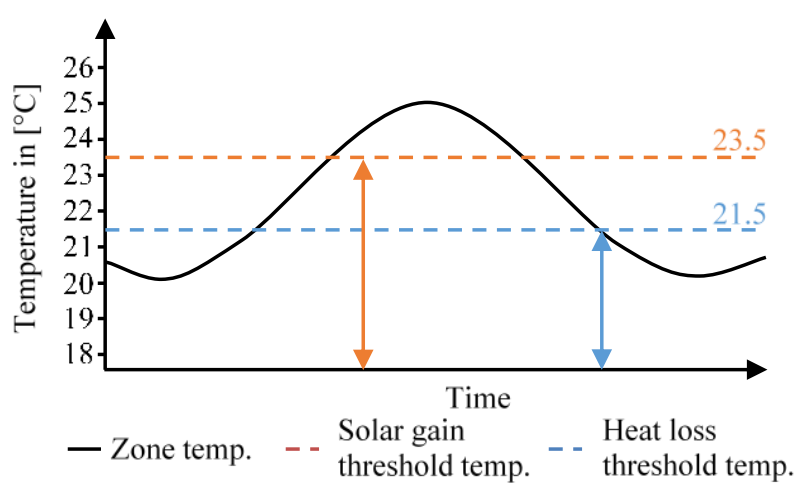

Figure 4: Heat gain and loss threshold temperatures.

With $21.5^{\circ} \mathrm{C}$, the heat loss threshold (HLT) temperature is $0.5 \mathrm{~K}$ higher than the heating setpoint temperature (HST) of $21.0^{\circ} \mathrm{C}$ which is the HST according to SN/TS 3031:2016. Heat losses above this value are not regarded to be generally detrimental, as they commonly do not induce the use of energy for heating. In analogy with the HLT, the solar gain threshold (SGT) temperature is $0.5 \mathrm{~K}$ below the cooling setpoint temperature (CST) of $24.0^{\circ} \mathrm{C}$ (which is the CST according to SN/TS 3031:2016), as there is usually no need for cooling below this temperature, even though the building does not have a cooling unit. The offset of $0.5 \mathrm{~K}$ to HST and CST are necessary to avoid the heating system to be active during times, in which no losses are counted. Due to control behaviour, the HST will never be kept precisely at $21.0{ }^{\circ} \mathrm{C}$ but sway around it within a certain range (ca. $\pm 0.1 \mathrm{~K}$ ) and the heating system in the zones is active below $21.5^{\circ} \mathrm{C}$.

To keep indoor conditions within the desired limits, energy in the same magnitude as the losses has to be supplied to the building. Generally, in ZEBs, a large fraction of this energy comes from electrical appliances, lighting, persons or solar gains. Therefore, the amount of heat losses is not to be equated with the heating energy demand. For the calculation of heating energy to be supplied in addition, e.g. over radiators or surface heating, SN/TS 3031:2016 gives internal loads as high as $42 \mathrm{kWh} / \mathrm{m}^{2} \mathrm{a}$ for residential buildings and $72 \mathrm{kWh} / \mathrm{m}^{2} \mathrm{a}$ for office buildings. In the case of ZEBs, internal loads contribute significantly to covering the heating demand.

For selecting the locations, available weather data of selected high latitude cities were analysed according to temperature variation, heating degree hours $\left(\mathrm{HDH}_{21 / 15}\right.$, since hourly weather data are used), annual global horizontal radiation and mean wind speed (see Figure 5). 
a)

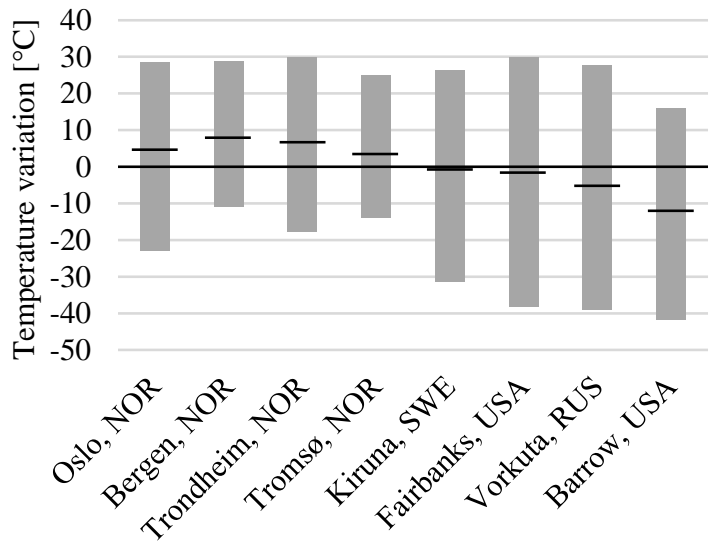

b)

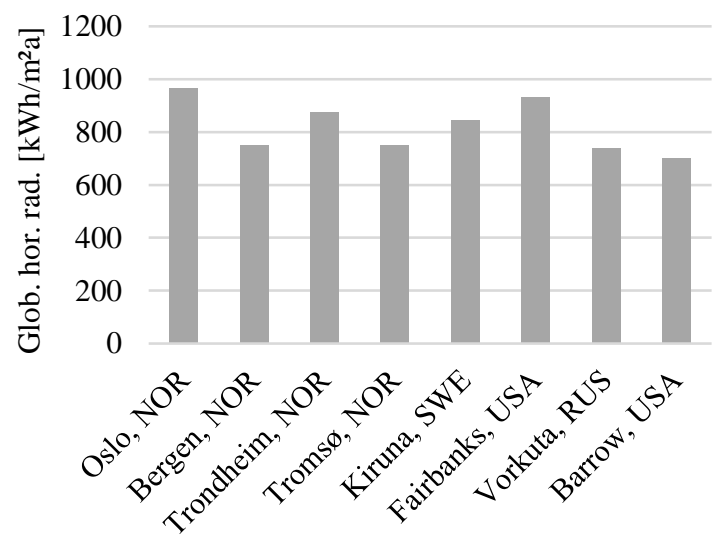

c)

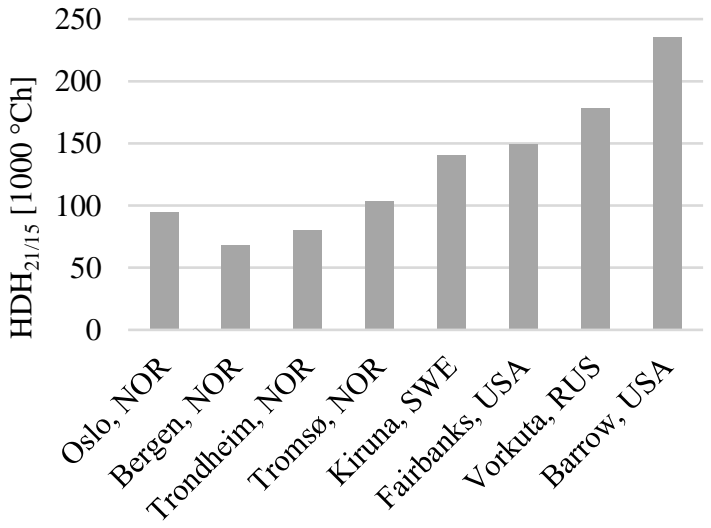

d)

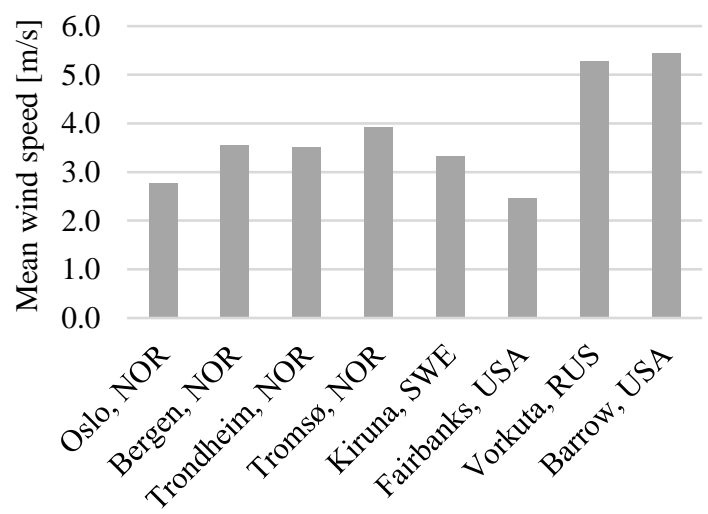

Figure 5: Comparison of locations with regard to a) temperature range and average; $b$ ) annual global horizontal radiation; c) $\mathrm{HDH}_{21 / 15}$; d) mean wind speed.
$\mathrm{HDH}_{21 / 15}$ describe the sum of hourly temperature differences between inside and outside over the year when hourly mean outdoor temperatures drop below $15^{\circ} \mathrm{C}$ at an indoor temperature of $21^{\circ} \mathrm{C}$.

The study aims to evaluate heat losses in buildings for typical weather conditions in high latitude cold climate regions. Due to the distribution of landmass, these regions are mostly located on the northern hemisphere, except for Antarctica. The locations were selected according to the following two criteria:

\section{- Latitude of at least $60^{\circ} \mathrm{N}$}

- Significant population or climate

The city of Oslo, however, located at $59.9^{\circ} \mathrm{N}$ was also included, as parts of the urban agglomeration and the site of the weather station at Oslo airport are located over $60^{\circ}$ N. Apart from Barrow, which was included due to its harsh and severe climate conditions, all cities have rather large populations (from $1.7 \times 10^{4}$ in Kiruna to over $1.0 \times 10^{6}$ for the agglomeration of Oslo). Other large cities over $60^{\circ} \mathrm{N}$ like for example Reykjavik in Iceland, Helsinki in Finland, Murmansk in Russia or the large cities in North America have not been included since their climate was too similar to the already selected locations.

This study evaluates where heat losses in ZEBs in cold climate occur, how they are distributed, and which climatic parameters influence them the most. The results will then deliver valuable information, which measures in terms of a neighbourhood setting may be most effective concerning its energy use. This study's outcome will then be used for further, more detailed investigations on the most important microclimatic parameters.

\section{Simulation cases}

As mentioned before, a central part of this study is the analysis of the influence of different wind conditions on the building's energy balance. This will be done for the LL as a residential (R) and an office building (O). The basis for this investigation is the wind speed and direction from the weather file. The wind speed at the building site (roof height, $V_{\text {loc }}$ ) is then calculated by the IDA ICE with the reference wind speed from the climate data set $\left(V_{\text {ref }}\right)$ the coefficients $a_{0}$ and $a_{\text {exp }}$, and the quotient of building height $h_{\mathrm{b}}$ to the reference height $h_{\text {ref }}$ of the wind measurement, as in Eq. 1 (Bring et al., 1999). The coefficients $a_{0}$ and $a_{\text {exp }}$ can be chosen from a database, as listed in Table 3, but can also be defined individually. Furthermore, pressure coefficients according to AIVC (sheltered, semi exposed, exposed) can be used. In the following simulations, three cases will be analysed:

1. "Open country" wind profile with "exposed" pressure coefficients $(\mathrm{OC} / \mathrm{E})$,

2. "Suburban" wind profile with "semi-exposed" pressure coefficients (SU/SE), and

3. "City centre" wind profile with "sheltered" pressure coefficients $(\mathrm{CC} / \mathrm{S})$

$$
V_{\text {loc }}=V_{\text {ref }} \cdot a_{0} \cdot\left(\frac{h_{\mathrm{b}}}{h_{\text {ref }}}\right)^{a_{\mathrm{exp}}}
$$




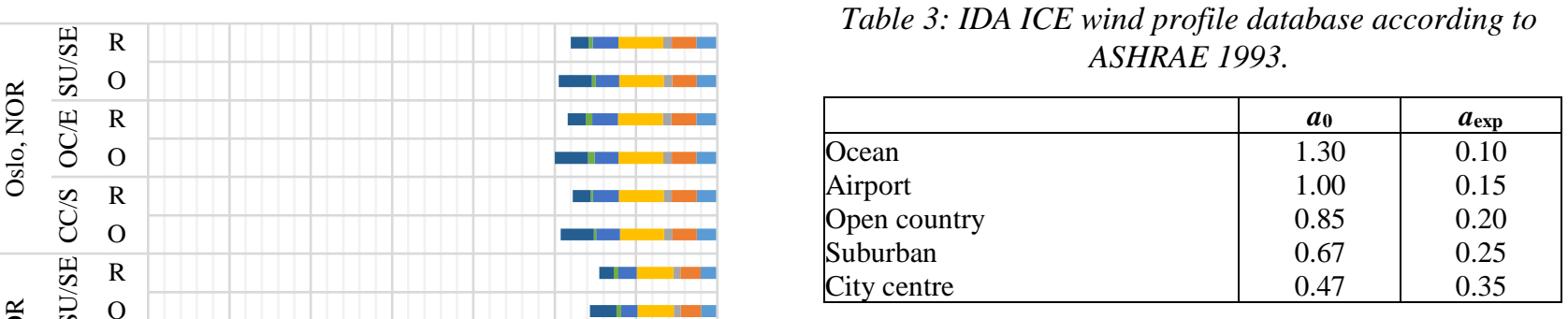

\section{Results}

Figure 6 displays the heat balance of the ZEB LL for the investigated cases in the eight selected locations. While in Bergen comparably little heat is lost, the extreme winter conditions in Barrow result in more than three times the energy losses in the residential (R) case and four times as much in the office $(\mathrm{O})$ case. The results show that the different wind conditions (OC/E, SU/SE, CC/S) influence a ZEB's energy balance in cold climate mostly relatively little (see Table 4).

Table 4: Maximum reduction of heat losses through wind sheltering (OC/E compared to CC/S)

\begin{tabular}{|l|c|c|}
\hline Location & Residential & Office \\
\hline Oslo, NOR & $-3.6 \%$ & $-3.6 \%$ \\
Bergen, NOR & $-6.8 \%$ & $-6.3 \%$ \\
Trondheim, NOR & $-4.8 \%$ & $-4.6 \%$ \\
Troms $\varnothing$, NOR & $-7.2 \%$ & $-6.4 \%$ \\
Kiruna, SWE & $-4.4 \%$ & $-4.1 \%$ \\
Fairbanks, USA & $-2.3 \%$ & $-1.9 \%$ \\
Barrow, USA & $-7.3 \%$ & $-6.0 \%$ \\
Vorkuta, RUS & $-8.3 \%$ & $-7.0 \%$ \\
\hline
\end{tabular}

Compared to the OC/E case, wind sheltering (CC/S) reduces energy losses only by $1.9 \%(\mathrm{O})$ to $2.3 \%(\mathrm{R})$ in Fairbanks, since its winter climate is characterized by low wind speeds. In contrast to that, even though mean wind speed in Barrow is even higher, savings of $7.0 \%(\mathrm{O})$ to $8.3 \%(\mathrm{R})$ can be obtained from proper wind sheltering in Vorkuta, because high wind speeds predominantly coincide with low outdoor temperatures.

Unsurprisingly infiltration losses are largely influenced by wind conditions. Compared to $\mathrm{CC} / \mathrm{S}$, wind-induced infiltration in OC/E-conditions doubled in Fairbanks and quadrupled in Bergen with an average increase of $222.6 \%$ (see Figure 7). There were no notable differences between the LL as a residential or an office building.

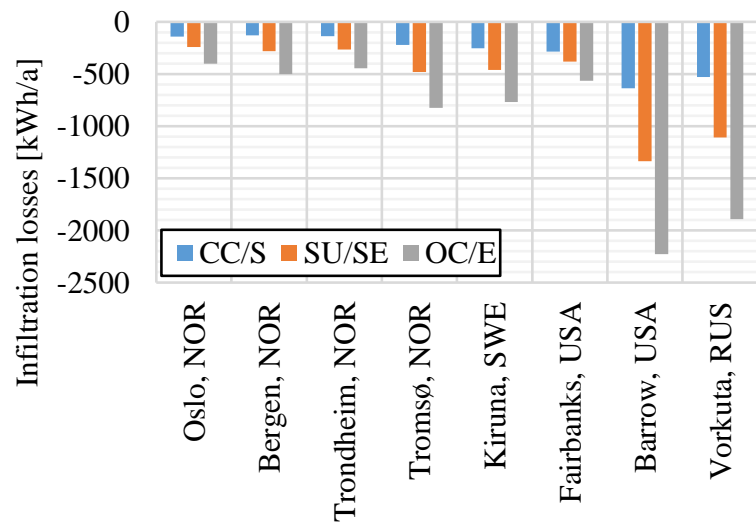

Figure 7: Infiltration losses of the ZEB LL as a residential building for different wind conditions 
Building envelope and ventilation losses remained relatively stable (changes below $2 \%$ ), even though wind speed is considered by the BEPS tool for the calculation of convective heat transfer coefficients. Figure 8 shows the envelope and infiltration heat losses as a function of the $\mathrm{HDH}_{21 / 15}$. The losses caused by the thermal bridges, floor, roof, walls and doors and windows show a strong dependency on $\mathrm{HDH}_{21 / 15}$ with $\mathrm{R}^{2}$ close to 1 . Infiltration losses correlate with $\mathrm{HDH}_{21 / 15}$ with an $\mathrm{R}^{2}$ of 0.821 as they partly also correlate with wind speed. From the slope of the linear regression line in Figure 8, it is visible that the losses from windows and walls and doors are stronger influenced by outdoor temperature.

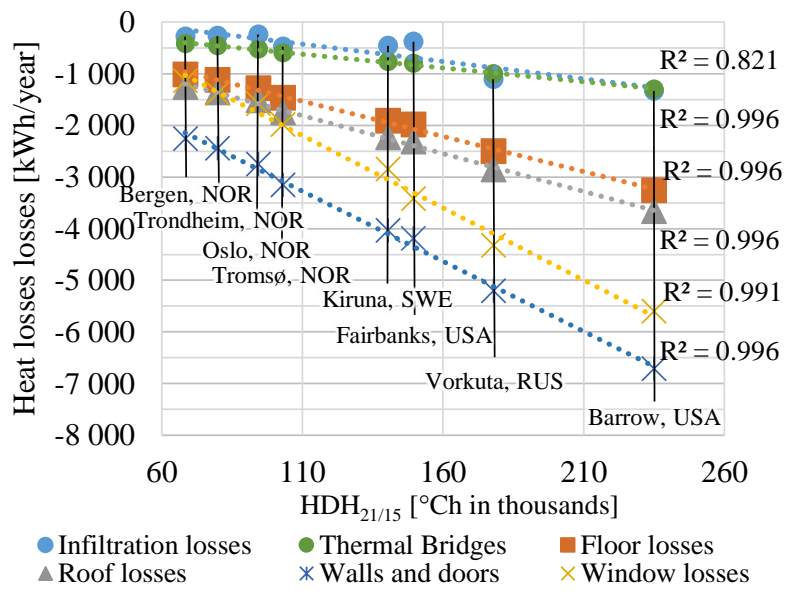

Figure 8: Envelope and infiltration losses as a function of $\mathrm{HDH}_{21 / 15}$ of the ZEB LL as a residential building with $S U / S E$ wind conditions

When looking at the ventilation losses, the relationship to $\mathrm{HDH}_{21 / 15}$ is not linear but exponential (see Figure 9). Whereas in Barrow, losses through the roof and the wall are about three times higher than in Bergen, ventilation losses differ with the factor 5 .

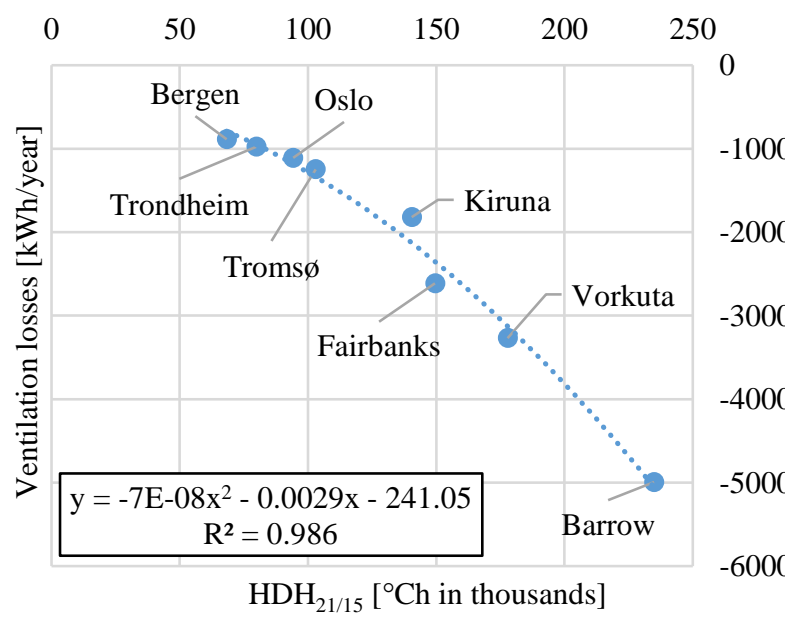

Figure 9: Ventilation losses of the ZEB LL as a residential building as a function of $\mathrm{HDH}_{21 / 15}$

It is visible as well in Figure 6 that ventilation losses in office buildings are approximately twice as high compared to residential buildings, resulting from more stringent requirements for ventilation rates in Norway. The differences between residential and office buildings are listed in Table 5.
Table 5: Overview of total heat losses of the ZEB LL in different locations as residential and office buildings in SU/SE wind conditions.

\begin{tabular}{|l|c|c|c|}
\hline Location & $\begin{array}{c}\text { Residential } \\
{[\mathbf{k W h} / \mathbf{a}]}\end{array}$ & $\begin{array}{c}\text { Office } \\
{[\mathbf{k W h} / \mathbf{a}]}\end{array}$ & $\begin{array}{c}\text { Difference } \\
{[-]}\end{array}$ \\
\hline Oslo, NOR & -9011 & -9756 & $-8.3 \%$ \\
Bergen, NOR & -7265 & -7837 & $-7.9 \%$ \\
Trondheim, NOR & -8025 & -8725 & $-8.7 \%$ \\
Troms, NOR & -10695 & -11607 & $-8.5 \%$ \\
Kiruna, SWE & -14091 & -15498 & $-10.0 \%$ \\
Fairbanks, USA & -15715 & -17757 & $-13.0 \%$ \\
Barrow, USA & -26865 & -31297 & $-16.5 \%$ \\
Vorkuta, RUS & -20271 & -23147 & $-14.2 \%$ \\
\hline
\end{tabular}

Windows take a special role in the energy balance of a building, as they can account for significant amounts of solar energy gains. Figure 10 illustrates the proportion of gains and losses in the respective locations. Especially in the Norwegian cities with around $40 \%$ of the total heat losses, useful solar gains significantly enhance the windows' overall energy balance. In Barrow, the highest amount of useful gains can be obtained, but losses overweigh the gains by the factor 5.5.

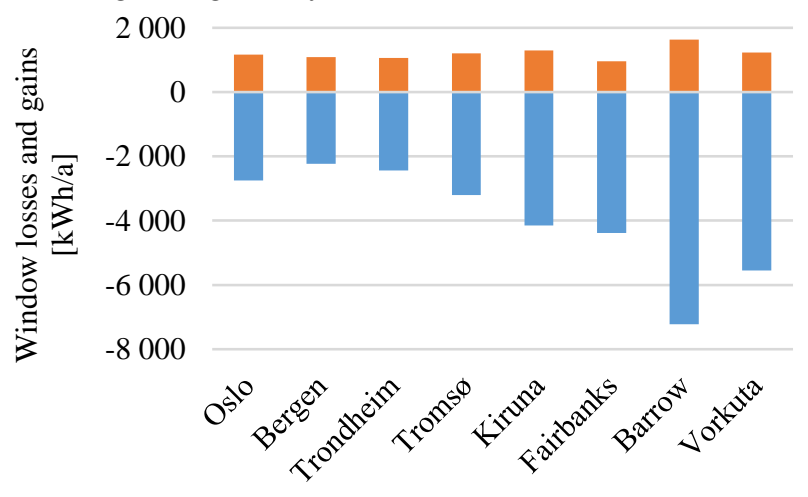

Figure 10: Unwanted losses and useful solar gains of windows in the ZEB LL as a residential building with SU/SE wind conditions.

\section{Discussion}

The IDA ICE simulations show a considerable variation of the distribution of heat losses, depending on the location's climate and the building's usage. Extremely low outdoor air temperatures affect ventilation losses stronger than e.g. envelope losses. The MVS and the HRU in particular face the problem of building up ice at very low temperatures and/or high moisture loads (Justo Alonso et al., 2015). In case of the ZEB LL, the HRU can operate until ca. $-15^{\circ} \mathrm{C}$ at full efficiency without building up ice. Below this temperature, preheating the air clearly deteriorates the overall efficiency and leads to a nonlinear correlation. While in the oceanic dominated climates of coastal Scandinavia, those extreme conditions occur only at rare intervals, the continental climate of its inland, central Alaska, or Siberia results in longer periods of extreme frost with temperatures dropping to -30 or even $-40^{\circ} \mathrm{C}$. Because of higher requirements for ventilation rates in office spaces from the Norwegian building code (NBC), ventilation losses are considerably higher. In all locations, windows account for a large fraction of heat 
losses, when only losses from conduction and longwave radiation are considered. The useful solar gains of west and east-oriented windows compensate for around $50 \%$ of unwanted losses over the year in the Norwegian cities. South-oriented windows can even have a positive energy balance with over $20 \%$ more useful energy gains than unwanted losses. These results support the findings by Grynning et al. (2013) that a window can outperform opaque building parts even in high-latitude locations when window properties, orientation etc. are chosen appropriately. Unwanted solar gains during summertime, on the other hand, increase the risk of overheating. This issue has not been considered in this study, though it generally should not be disregarded. In the nonNorwegian locations, none of the ZEB LL's windows came close to a positive annual energy balance.

Floor and roof of the LL account for large fractions of total the total envelope area, as it only consists of one storey (building envelope area $A$ to volume $V$ ratio $\left.A / V=1.1 \mathrm{~m}^{-1}\right)$. Therefore, these building parts also account for a high share of the building's total heat losses. In larger multi-storey residential or office buildings, the envelope losses will account for a lower fraction of total heat losses (with $A / V$ as low as $0.2 \mathrm{~m}^{-1}$ ), which puts more importance on ventilation losses as they are a function of a building's floor area. The distribution of heat losses for the ZEB LL in the different locations can be seen in Figure 11 and Figure 12.

It is worth noting that floor losses in IDA ICE are calculated according to ISO 13370 (International Standard Organisation, 2017). The program determines the heat resistance of the ground layer based on the geometry of the building and the heat conductivity of the ground material (kept at its default values with thermal conductivity $\lambda=2.0 \mathrm{~W} /(\mathrm{mK})$, density $\rho=2000 \mathrm{~kg} / \mathrm{m}^{3}$, and heat storage capacity $c=1000 \mathrm{~kJ} / \mathrm{kg}$ ). According to ISO 13370, the ground temperature is calculated as a weighted average value of the annual and the monthly mean air temperatures, including a given time lag.

However, the study is limited by the fact that the ZEB LL cannot be regarded as a typical office building. In addition, the results are not generalisable for singlefamily homes in the selected locations either, apart from the Norwegian ones because input parameters for the simulations are based on the NBC. Country-specific regulations in the non-Norwegian locations would certainly lead to different results. However, because the focus in this study was put on the influence of climate, results are only comparable when using an identical input.

Other limiting aspects are the weather data. Mostly, they have been recorded at the locations' airports, often more than $20 \mathrm{~km}$ away. The wind situations there may be entirely different from what an average building in the cities might experience. The same limitation applies to solar irradiation, as no mutual shadowing was accounted for in this study. Beyond, especially when it comes to the influence of wind, BEPS programs are not very well suited for meaningful quantitative analyses. For that, computational fluid dynamics (CFD) programs should be used to evaluate reasonable boundary conditions. Moreover, this study is based on self-defined thresholds as there are no official definitions of useful gains and unwanted or detrimental losses. Different definitions may, therefore, lead to different results.

\section{Conclusion}

In this study, a validated model of the ZEB Living Laboratory, located on the campus of the Norwegian University of Science and Technology in Trondheim, Norway, was simulated at different locations in cold climate to analyse the distribution of heat losses. While envelope and infiltration losses were found to be linearly dependent on the number of heating degree hours, ventilation losses revealed to have an exponential relationship. When using the Norwegian building code for the input parameters, the main difference between residential $(\mathrm{R})$ and office $(\mathrm{O})$ building was found to be the ventilation losses due to more stringent requirements for ventilation rates in offices.

Whereas the presented results might seem rather selfevident, such quantitative analysis of heat losses in a ZEB in cold climate conditions can be regarded as the first step towards a comprehensive analysis of microclimatic effects on ZEBs and delivers useful information on how heat losses are distributed. The setting of a Zero Emission Neighbourhood not only impacts the wind sheltering situation which is able to reduce heat losses by $1.9 \%(\mathrm{O})$ to $2.3 \%(\mathrm{R})$ in Fairbanks and $7.0 \%(\mathrm{O})$ to $8.3 \%(\mathrm{R})$ in Vorkuta.

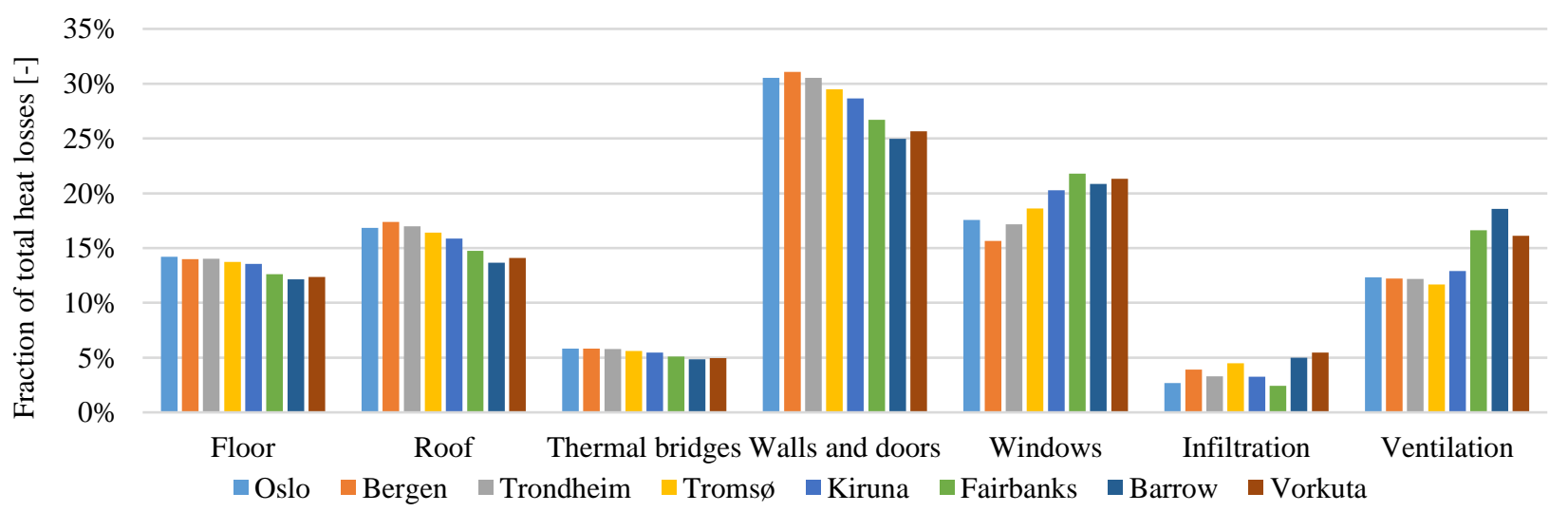

Figure 11: Distribution of heat losses for the ZEB LL as a residential building for SU/SE wind conditions. 


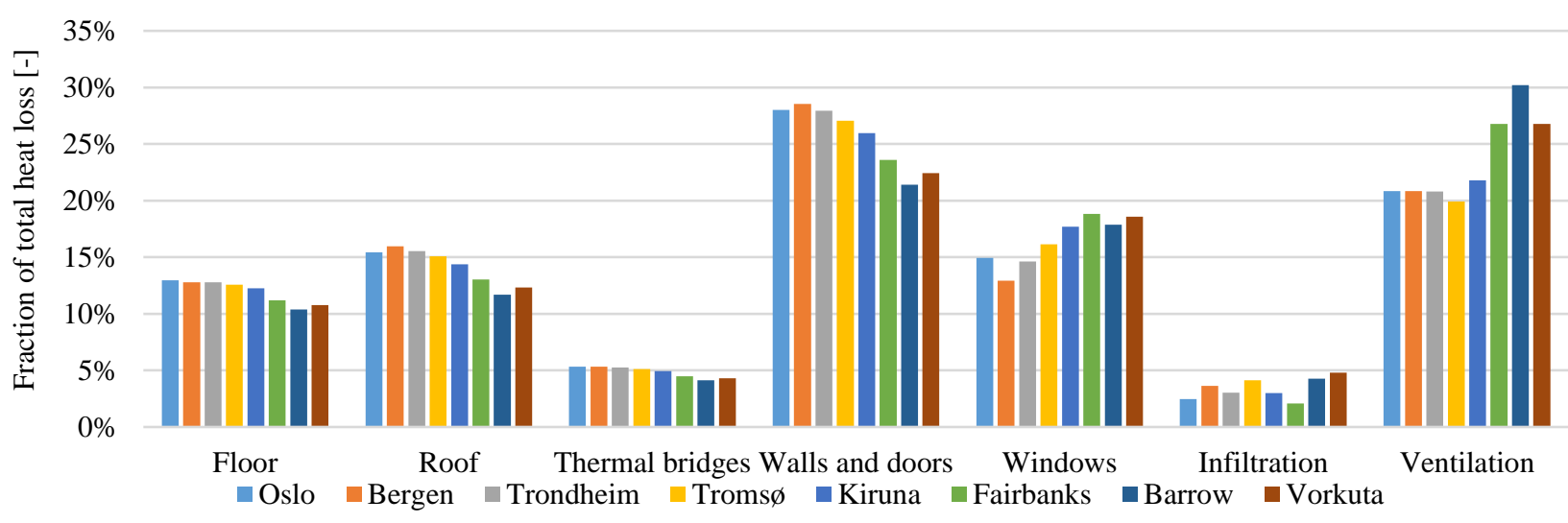

Figure 12: Distribution of heat losses for the ZEB LL as an office building for SU/SE wind conditions.

It also influences solar accessibility, which was found to account for significant amounts of solar gains. Windows can, in fact, outperform opaque building parts, even in high-latitude locations.

Additional investigations of different kinds of buildings, regarding their shape, usage and material properties need to be carried out to further quantify the impact of microclimatic aspects on a ZEB's energy balance. For that, measurements and simulations are currently carried out on FME ZEN's pilot projects as case studies.

\section{Acknowledgements}

This paper has been written within the Research Centre on Zero Emission Neighbourhoods in Smart Cities (FME ZEN). The authors gratefully acknowledge the support from the ZEN partners and the Research Council of Norway.

\section{References}

American Society of Heating, Refrigerating and AirConditioning Engineers (2009): 2009 ASHRAE handbook. Fundamentals. SI ed. Atlanta GA: American Society of Heating Refrigeration and AirConditioning Engineers.

Bring, A.; Sahlin, P.; Vuolle, M. (1999): Models for Building Indoor Climate and Energy Simulation. A Report of IEASHCTask 22: Building Energy Analysis Tools, Subtask B: Model Documentation. Edited by KTH Stockholm.

Building Performance Institute Europe (2011): Europe's buildings under the microscope. A country-by-country review of the energy performance in buildings. Edited by Building Performance Institute Europe (BPIE), checked on $1 / 3 / 2019$.

Edenhofer, O. (Ed.) (2014): Climate Change 2014: Contribution of Working Group III to the Fifth Assessment Report of the Intergovernmental Panel on Climate Change. Mitigation of climate change. IPCC. New York (USA): Cambridge Univ. Pr.

Goia, F.; Finocchiaro, L.; Gustavsen, A. (2015): The ZEB Living Laboratory at the Norwegian University of Science and Technology: a zero emission house for engineering and social science experiments. In 7th Passivhus Norden - Conference Proceedings.

Grynning, S.; Gustavsen, A.; Time, B.; Jelle, B. P. (2013): Windows in the buildings of tomorrow: Energy losers or energy gainers? In Energy and Buildings 61, 185192.

Hestnes, A. G.; Eik-Nes, N. L. (Eds.) (2017): Zero emission buildings. Bergen (Norway): Fagbokforlaget.

International Standard Organisation (2017): Thermal performance of buildings - Heat transfer via the ground - Calculation methods (ISO 13370).

Justo Alonso, M.; Liu, P.; Mathisen, H. M.; Ge, G.; Simonson, C. (2015): Review of heat/energy recovery exchangers for use in ZEBs in cold climate countries. In Building and Environment 84, 228-237.

Liddament, M. W. (1986): Air Infiltration Calculation Techniques - An application guide. Edited by The Air Infiltration and Ventilation Centre. Coventry (UK).

Moonen, P.; Defraeye, T.; Dorer, V.; Blocken, B.; Carmeliet, J. (2012): Urban Physics: Effect of the micro-climate on comfort, health and energy demand. In Frontiers of Architectural Research 1 (3), 197-228.

Norwegian Building Authority (2017): Regulations on technical requirements for construction works.

Oke, T. R.; Mills, G.; Christen, A.; Voogt, J. A. (2017): Urban climates. Cambridge: Cambridge University Press.

Peel, M. C.; Finlayson, B. L.; McMahon, T. A. (2007): Updated world map of the Köppen-Geiger climate classification. In Hydrology and Earth System Sciences Discussions 4 (2), 439-473.

Sargent, R. G. (2013): Verification and validation of simulation models. In Journal of Simulation 7 (1), 12 24.

Watkins, R.; Palmer, J.; Kolokotroni, M. (2007): Increased Temperature and Intensification of the Urban Heat Island: Implications for Human Comfort and Urban Design. In Built Environment 33 (1), 85 96. 